
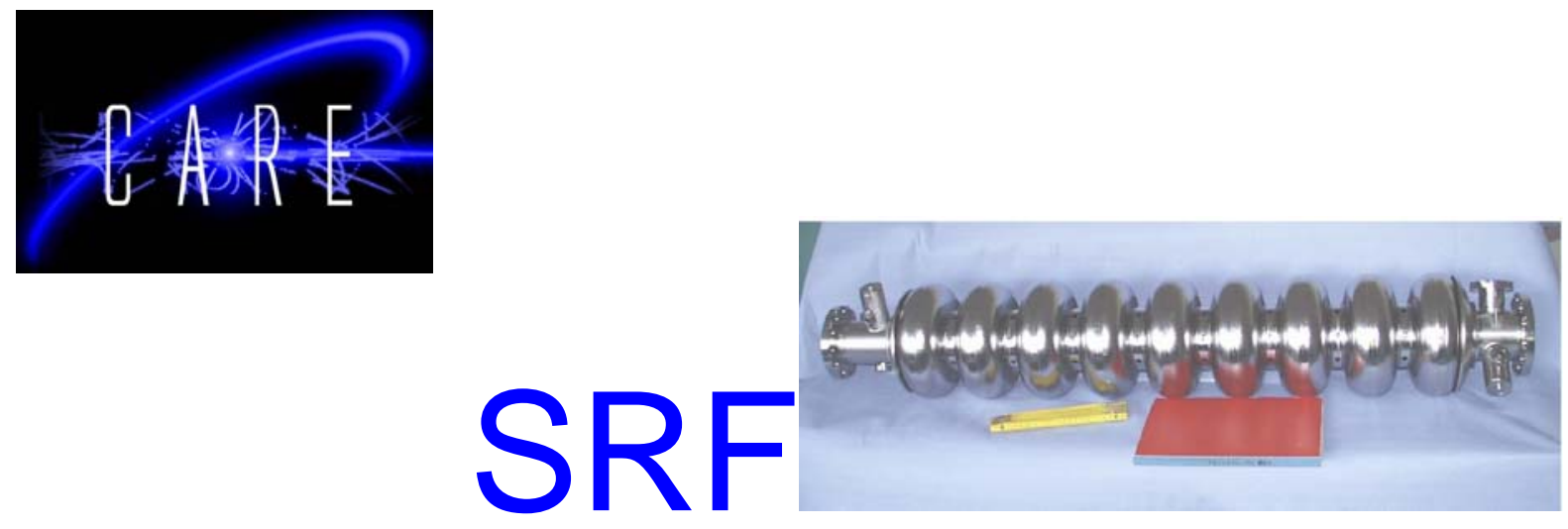

\title{
ELECTRO-POLISHING SURFACE PREPARATION FOR HIGH GRADIENT CAVITIES AT DESY
}

A. Matheisen, H.Morales, B. Petersen, M.Schmökel, N. Steinhau-Kuehl Deutsches Elektronen Synchrotron DESY, Hamburg, Notkestraße 85, 22602 Hamburg, Germany

\begin{abstract}
Improvement of acceleration gradients in super conducting accelerator structures was reached by applying electro polishing to the niobium surfaces. This technology is actually foreseen to serve as major surface preparation step for projects like the XFEL at DESY and the proposed ILC linear accelerator. At DESY an electro polishing apparatus was build up in 2003. After commissioning the apparatus operates regular for cavity surface treatment. We report on experiences with the electro-polishing set up, polishing parameters and results on the preparation of S.C. resonators for a high gradient module to be tested in the TTF2 accelerator at DESY.
\end{abstract}

Contribution to the PAC05, Knoxville, USA

Work supported by the European Community-Research Infrastructure Activity under the FP6 "Structuring the European Research Area" programme (CARE, contract number RII3-CT2003-506395). 


\title{
ELECTRO-POLISHING SURFACE PREPARATION FOR HIGH GRADIENT CAVITIES AT DESY
}

\author{
A. Matheisen, H.Morales, B. Petersen, M.Schmökel, N. Steinhau-Kuehl
}

Deutsches Elektronen Synchrotron DESY, Hamburg, Notkestraße 85, 22602 Hamburg, Germany

\begin{abstract}
Improvement of acceleration gradients in super conducting accelerator structures was reached by applying electro polishing to the niobium surfaces. This technology is actually foreseen to serve as major surface preparation step for projects like the XFEL at DESY and the proposed ILC linear accelerator. At DESY an electro polishing apparatus was build up in 2003. After commissioning the apparatus operates regular for cavity surface treatment. We report on experiences with the electro-polishing set up, polishing parameters and results on the preparation of S.C. resonators for a high gradient module to be tested in the TTF2 accelerator at DESY.
\end{abstract}

\section{INTRODUCTION}

The electro polishing apparatus (EPA), installed in 2003 at DESY, serves as major surface preparation tool for the TTF /XFEL accelerator structures at DESY now[1]. More than 100 hours of electro polishing (EP) is applied on the nine cell resonator geometry now. Several resonators with different history have undergone the polishing process and are measured with radio frequency power (rf)at $2 \mathrm{~K}$.

For Projects like the XFEL [2] and the proposed ILC linear accelerator [3] questions like reproducibility of gradients, system parameters and hardware reliability are studied. We report on results gained so far on the apparatus and parameter settings.

\section{ELECTRO POLISHING SET UP}

The EPA is located outside of the DESY/TTF cleanroom. The DESY EPA is designed as a closed loop rotation speed of the horizontal located cavity is 1 turn per minute. A total of 40 sensors are installed to control the automated process sequences [2] (Figure 1) and to ensure system safety. To drain and to rinse off the acid the resonator is turned to vertical position.

\section{COMPONENTS}

Several components of the EPA are exchanged in respect to the basic lay out [4]. These changes are done for improvement of safety, process steering and reliability of components.

\section{Sensors}

The benefit of high sensitivity and self safe lay out of electronic sensors like capacitive and inductive once can not be used in the acid lines. The high viscosity and high surface adhesion of the acid does not allow applying these sensors for level control and process steering. Delay times of up to one minute are measured. Capacitive sensors were exchanged to read relays with signal feedback below one second.

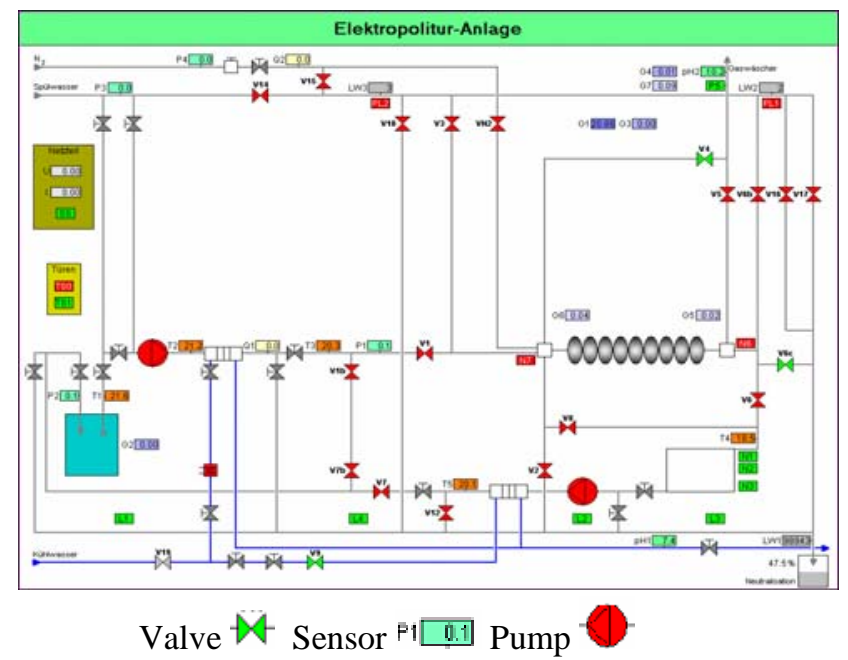

Figure 1: Flow chart of the DESY electro polishing infrastructure.

\section{Material}

PVDF material in use for tanks and heat exchangers showed significant corrosion after 100h. Tubes and sensors made from PFA are not affected. Strong corrosion is seen on the pure Aluminium (99.9) electrode as well. Commercial heat exchangers, made from PVDF, showed leaks after 3 month of exposure to the EP mixture. The sump, made from PVDF as well, is exposed to the acid at temperatures above $30 \mathrm{C}^{\circ}$. It had to be replaced after 100 hours (Fig.2).

A significant penetration of Hydro-Fluoride threw PVDF- and PFA tubes is measured [6]. Cooling waters of the heat exchanger needed

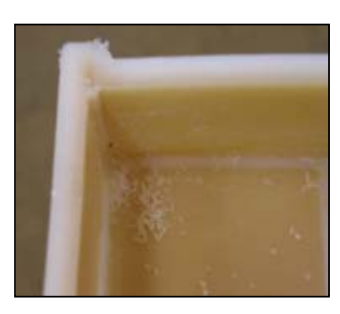

to be decontaminated before disposal.

Figure 2: cross section of PVDF wall (sump container).

\section{EP Head}

End heads, closing the cavity beam tubes, are made from PVDF and are equipped with axial rotary shaft seal. Three out of 4 seals (Viton F®) leaked after 25h. Rotary 
shaft seals made out of PTFE are under investigation and stand for 50 hour without failure now.

\section{Hf Absorber}

Strong out-gassing of Hf gas is observed [6]. The basic principle of commercial gas scrubber consists in solving the gases in water. They failed completely and could not reduce the Hf amount significantly. Hf absorbers filled with Garnular dry absorber material (COSA-D ${ }^{\circledR}$ ) are installed directly on the pipes of the cavity and storage vessel outlet; venting exit; sump tank venting pipe). They show best results with acceptable costs and live time.

\section{Sulphur Sedimentation}

The actual EP parameters (acid mixture, material combination and temperatures) can lead to sulphur segregation [7]. This segregation can form monolithic

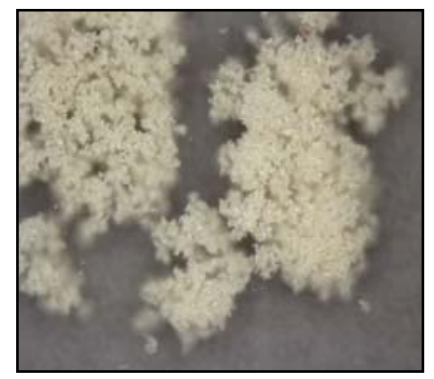
crystals. Large areas of the DESY EP apparatus are covered by sulphur sediment

(Fig.: 3)

Figure 3: sulphur

sediment (magnified $* 10$ ).

\section{EP Parameter}

The EP at DESY bases on constant voltage applied to the process. Due to the leg of reliable heat exchangers a

\begin{tabular}{|l|l|l|l|l|}
\hline \multicolumn{5}{|c|}{ Table 1:Parameter set of the EP process at DESY } \\
\hline & New acid & Unit & Used acid & Unit \\
\hline $\begin{array}{l}\text { Time in } \\
\text { use }\end{array}$ & 0 & minutes & 600 & minutes \\
\hline Nb content & 0 & $\mathrm{gr} / \mathrm{l}$ & $10-12$ & $\mathrm{gr} / \mathrm{l}$ \\
\hline HF content & 2,78 & $\mathrm{Mol} / \mathrm{l}$ & $\sim 1,9$ & $\mathrm{Mol} / \mathrm{l}$ \\
\hline $\begin{array}{l}\text { Acid } \\
\text { volume }\end{array}$ & 150 & $\mathrm{l}$ & 140 & $\mathrm{~L}$ \\
\hline Voltage & 17 & $\mathrm{~V}$ & 17 & $\mathrm{~V}$ \\
\hline Current & 320 & $\mathrm{~A}$ & 210 & $\mathrm{~A}$ \\
\hline $\begin{array}{l}\text { Current } \\
\text { density }\end{array}$ & 5,81 & $\mathrm{~A} / \mathrm{dm}^{2}$ & 4,9 & $\mathrm{~A} / \mathrm{dm}^{2}$ \\
\hline Oscillation & $+44-66$ & $\mathrm{~A}$ & $+43-73$ & $\mathrm{~A}$ \\
\hline $\begin{array}{l}\text { Removal } \\
\text { rate }\end{array}$ & 0,445 & $\mu \mathrm{m} / \mathrm{min}$ & 0,36 & $\mu \mathrm{m} / \mathrm{min}$ \\
\hline $\begin{array}{l}\text { injection } \\
\text { speed per } \\
\text { cell }\end{array}$ & $5,3-5,6$ & $\mathrm{~m} / \mathrm{sec}$ & $5,9-6,5$ & $\mathrm{~m} / \mathrm{sec}$ \\
\hline $\begin{array}{l}\text { Acid } \\
\text { circulation }\end{array}$ & $9-9,5$ & $\mathrm{l} / \mathrm{min}$ & $10-11$ & $\mathrm{l} / \mathrm{min}$ \\
\hline
\end{tabular}

Temperature stabilization is not feasible jet. Only cooling of the acid refilled into the storage vessel without temperature stabilization is possible. The correlation of removal rate and process temperature can actually not be measured. A strong dependency of the in use time of the acid and the removal rates are seen (Fig.4). Investigations show that the use up of the $\mathrm{Hf}$ component is the dominating effect for aging [8].

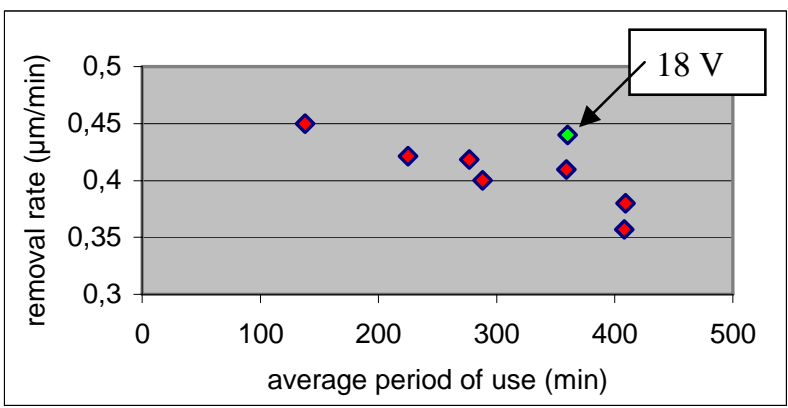

Figure 4: Removal rates and aging of the EP Mixture HF/H2SO4 (1/9). Removal rates measured for $U=17 \mathrm{~V}$ constant voltage.

\section{ACCELERATION GRADIENTS}

Before starting up EP at DESY 10 cavities out of the 3rd cavity production sequence were electro polished in collaboration with KEK [9]. Cavities not reaching the goal of $35 \mathrm{MV} / \mathrm{m}$ within that champagne got additional polishing at the DESY EP. These cavities are summarized in Cat1.

Two cavities of category 1 reached acceleration gradients of more than $35 \mathrm{MV} / \mathrm{m}$ after 2 more EP treatments $120 \mathrm{C}^{0}$ baking (Fig.:5;6).

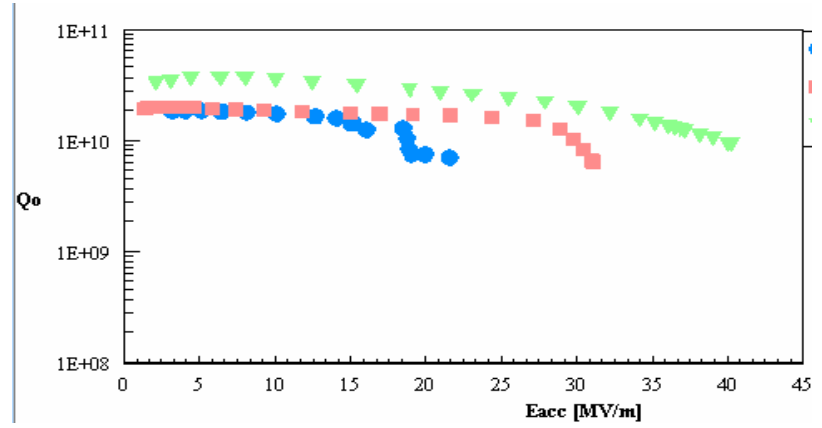

Figure 5: Acceleration gradients of cavity AC 70 (blue= before EP at DESY; red= after EP at DESY; green= after $120 \mathrm{C}$ baking)

Three Cavities reached $35 \mathrm{MV} / \mathrm{m}$ within the collaboration efforts. They degraded after test due to not qualified handling or problems on the infrastructure.

\begin{tabular}{|c|c|c|}
\hline \multicolumn{3}{|c|}{ Table1: treatment sequences for EP cavities at DESY } \\
\hline Category 1 & Category 2 & Category 3 \\
\hline $\begin{array}{l}\text { Cavity production } \\
\text { No } 3\end{array}$ & $\begin{array}{l}\text { Cavity production No } \\
3\end{array}$ & $\begin{array}{l}\text { Cavity production } \\
\text { No } 32 \text { different } \\
\text { suppliers }\end{array}$ \\
\hline $80 \mu \mathrm{m} \mathrm{BCP}$ & $2 * 80 \mu \mathrm{m}$ BCP & 2* $90 \mu \mathrm{m} \mathrm{EP}$ \\
\hline $\begin{array}{l}1400 \mathrm{C} \text { Ti post } \\
\text { purification }\end{array}$ & $\begin{array}{l}100 \mu \mathrm{m} \text { electro EP } \\
\text { (collaboration with } \\
\text { KEK ) }\end{array}$ & 800C annealing \\
\hline $80 \mu \mathrm{m} \mathrm{BCP}$ & Qualified $\rightarrow 35 \mathrm{MV} / \mathrm{m}$ & $\mathrm{n}$ times $40 \mu \mathrm{m} \mathrm{EP}$ \\
\hline $\begin{array}{l}100 \mu \mathrm{m} \text { EP in } \\
\text { collaboration with } \\
\text { KEK at KEK }\end{array}$ & $\begin{array}{l}\text { Degradation due to } \\
\text { handling/ } \\
\text { infrastructure }\end{array}$ & \\
\hline $\begin{array}{c}\text { not qualified } \\
<35 \mathrm{MV} / \mathrm{m}\end{array}$ & $\mathrm{N}$ times $40 \mu \mathrm{m} \mathrm{EP}$ & \\
\hline $\mathrm{n}$ times $40 \mu \mathrm{m} \mathrm{EP}$ & Not recovered & \\
\hline
\end{tabular}


These cavities are summarized as category 2 cavities.

Category 3 involves all cavities of the latest cavity production campaign. These cavities did not undergo 1400 Co post purification. All surface removal of Cat.3 cavities is done by EP only.

\section{Test Results}

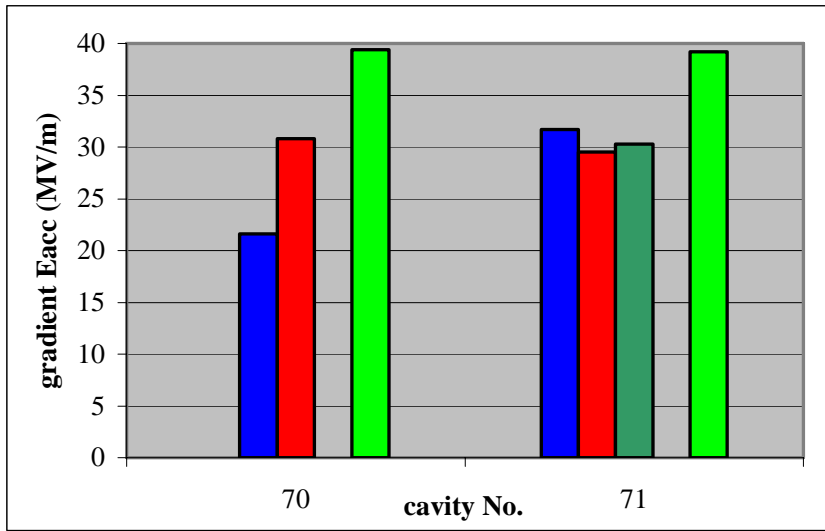

Figure 6: development of acceleration gradients for category 1 cavities (blue= before EP at DESY; red=1st; dark green=2nd EP run at DESY; light green= + $120 \mathrm{C}$ baking) .

Category 2 cavities degraded from $35 \mathrm{MV} / \mathrm{m}$ due to handling or infrastructure problems. The influence and depth of the impact on the Niobium surface is not known. These cavities did not recover completely jet, even after removal of more than $50 \mu \mathrm{m}$ by electro polishing (Fig.7).

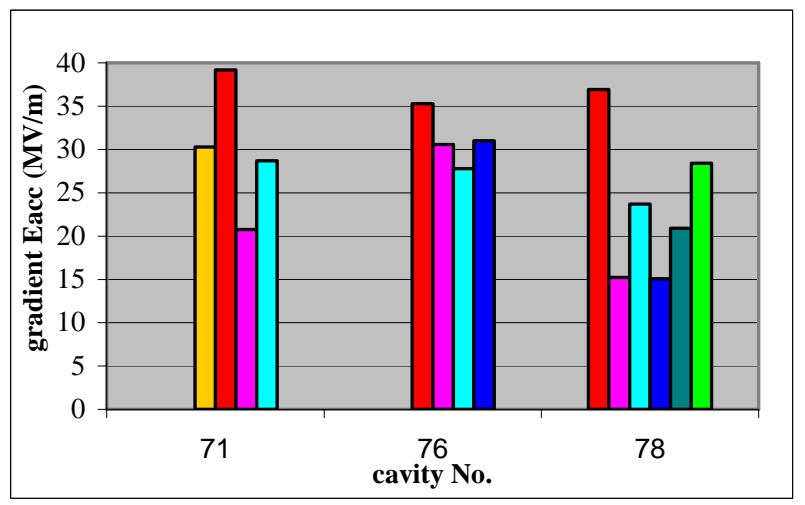

Figure 7: development of the acceleration gradient of category 2 cavities (red= Start value; violet= degradation; light blue $=$ first, dark blue $=$ second, dark green $=$ third, light green= fourth re-polishing).

Three cavities of the new cavity production are limited below $27 \mathrm{MV} / \mathrm{m}$ by break down in the equator weld region, origin form production errors (Fig.:8). After reestablishing the production sequences the latest cavity is not limited at a weld region. It reaches $33 \mathrm{MV} / \mathrm{m}$, limited by RF power and shows the typical $\mathrm{Q}$ degradation of EP resonators at high field before $120 \mathrm{C}^{0}$ baking [10].

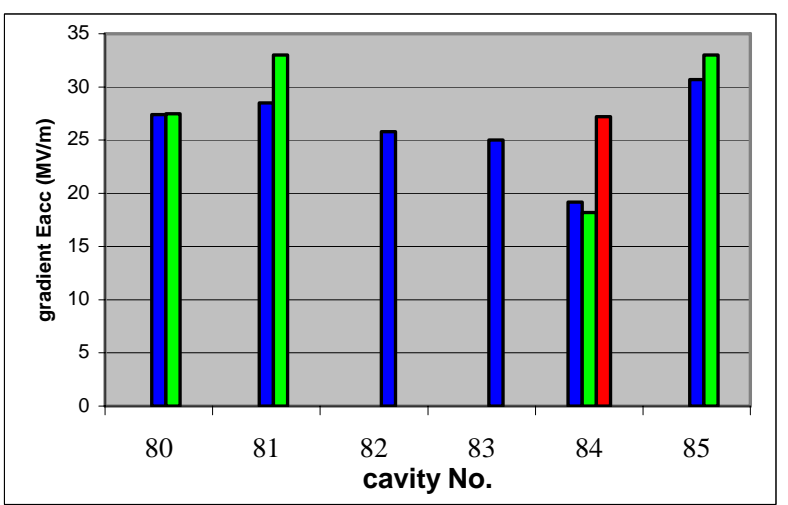

Figure 8: acceleration gradient of category 3 cavities (blue= start value; green= first, red= second re-polishing).

\section{CONCLUSION}

The DESY EP apparatus is running continuously since 100 hours and serves as a major preparation facility now. Unexpected material and reliability problems showed up. Solutions for these are under investigation. Sulphur sedimentations are observed during apparatus maintenances. The origin as well as the influence of the sulphur monoliths on field emission loading of electro polished cavities is under study.

The reproducibility of acceleration gradient above 35 $\mathrm{MV} / \mathrm{m}$ is lower than expected. Two 9 cell resonators reached acceleration gradients of more than $38 \mathrm{MV} / \mathrm{m}$. A new cavity production fulfils the requirements of the TTF / XFEL gradient requested. It is shown that these gradients can be reached without post purification at 1400 C. It is proven that gradients above $35 \mathrm{MV} / \mathrm{m}$ are gained without post purification at $1400 \mathrm{C}$ as well.

\section{REFERENCES}

[1] TESLA Technical Design Report DESY 2001-011 DESY Hamburg, Germany, March 2001

[2] TESLA/ XFEL TDR supplement October 2002 DESY Hamburg,Germany; http://tesla.desy.de

[3] Proceedings of the first ILC workshop 2004,KEK 1-1Oho,Tsukuba Ibaraki, Japan

[4] Proceedings of the $10^{\text {th }}$ workshop on RFsuperconductivity 2001, Tsukuba Ibaraki, Japan, K.Escherich et all ; PT 015

[5] Proceedings of the $11^{\text {th }}$ workshop on RFsuperconductivity 2003, Travemünde, Germany, H. Morales et all.; TuP 54

[6] Proceedings of the XXII Linac Conference 2004 Lübeck,Germany, A.Matheisen THP 95

[7] A.Aspard ; CEA-Saclay; France; private communication; to be published.

[8] N.Steinhau-Kühl this conference 2871 TPPT0057

[9] TESLA ITRP visit5.6thApril 2004; DESY Hamburg, Germany:http://tesla.desy.de/newpages/hamburg_me eting_4_2004/Posters/CAV04

[10] Proceedings of the workshop on pushing the limits of RF superconductivity; 22-24.September 2004; Argonne national lab; ANL -05/10 H.Padamsee.P119 